\title{
Effect of Carving in Pharmacy Benefits on Utilization and Costs
}

\author{
Natasha Parekh, MD, MS; Sarah Papa, MS; Alek Drnach, MS; Laura Spiegel, BS; Yan Huang, MS;
} Chronis Manolis, RPh; and Chester B. Good, MD, MPH

\begin{abstract}
BACKGROUND: Rising medical costs are a significant concern for employers offering health benefits to employees, and there is interest in identifying insurance plan designs that optimize the effect of pharmacy benefits on overall costs. For instance, employers must decide between plans that carve in pharmacy benefits (where medical and pharmacy benefits are integrated into 1 package through an insurer) versus plans that carve out pharmacy benefits (where pharmacy benefits are separately administered through a pharmacy benefit manager). Little is known about the effect of carving in pharmacy benefits on medical utilization and costs.
\end{abstract}

OBJECTIVE: To compare the effect of carving in versus carving out pharmacy benefits on medical utilization, medical costs, and health management program participation in commercial health plans.

METHODS: We performed a propensity score-matched analysis comparing carve-in and carve-out members of a regional health plan in 2018. Our primary outcomes were medical utilization (annual medical claims/1,000 members) and costs (medical costs per member per month [PMPM]). We categorized these into the following domains: inpatient, emergency department, outpatient/ambulatory surgery, urgent care, primary care, specialist services, and diagnostics (laboratory testing/imaging). We additionally assessed participation in health plan-based health management programs.

RESULTS: We analyzed 9,633 carve-in members matched with 9,633 carve-out members. Compared with carving out pharmacy benefits, carving in was associated with $3.7 \%$ lower medical costs, with an $\$ 8.73$ reduction in PMPM (\$225.87 vs. \$234.60), and no significant difference in medical utilization; significantly lower inpatient and urgent care claims (reduction of 9.29 claims $/ 1,000$ and 51.3 claims $/ 1,000$, respectively) and costs $(\$ 10.08$ and \$0.12 PMPM reduction, respectively); lower injectable medical therapy costs (\$4.32 PMPM reduction); and higher durable medical equipment costs (\$2.14 PMPM increase). Carve-in members also experienced $4.9 \%$ higher health management program participation.

CONCLUSIONS: As employers attempt to understand the value of carving in versus carving out pharmacy benefits to health plans, our findings suggest that carving in pharmacy benefits is associated with reduced medical costs and hospitalizations. Our findings can assist in informing employer decision-making processes and, as a result, reducing costs of care.

J Manag Care Spec Pharm. 2020;26(10):1317-24

Copyright $\odot 2020$, Academy of Managed Care Pharmacy. All rights reserved.

\section{What is already known about this subject}

Rising medical costs are a significant concern for employers offering health benefits for employees, and there is interest in identifying insurance plan designs that optimize the effect of the pharmacy benefit on overall costs of care.

Benefit design options for employers include carve-in plans, where the health plan vendor provides medical and pharmacy benefits, and carve-out plans, where the health plan vendor provides medical benefits but pharmacy benefits are carved out to a pharmacy benefit manager.

\section{What this study adds}

In this propensity score-matched analysis comparing medical utilization and medical costs among carve-in pharmacy versus carve-out members of a large commercial health plan, carving in pharmacy benefits was associated with significantly lower total medical costs with no change in total medical claims, significantly lower inpatient and urgent care claims and costs, lower injectable medical therapy costs, and higher durable medical equipment costs.

Carving in pharmacy benefits was associated with higher participation in insurer-based health management programs.

As employers attempt to understand the value of carving in versus carving out pharmacy benefits to health plans, our findings can be instrumental in informing employers' decision-making processes and, as a result, reducing costs of care.
$\mathrm{M}$ edical costs are anticipated to rise by $5 \%-6 \%$ in 2020 , with drug spending being a key driver. ${ }^{1}$ Rising costs are a significant concern for employers offering health benefits for employees, and there is substantial interest in identifying insurance plan designs that optimize the effect of the pharmacy benefit on overall costs of care. When employers consider health plan options, benefit design options include carve-in plans, where the health plan vendor offers medical and pharmacy benefits in an integrated package, and carve-out plans, where the health plan vendor provides medical benefits, but pharmacy benefits are carved out via a direct arrangement between an employer and pharmacy benefit manager (PBM). ${ }^{2}$

In carve-in plans, the health plan vendor may administer its pharmacy benefits in-house or may contract with a PBM for some or all aspects of pharmacy benefit management. When health plans contract with PBMs in carve-in designs, 
they decide which pharmacy administration functions (e.g., claims processing, customer service, formulary management, and clinical policy administration) to designate to PBMs and which to retain in house., ${ }^{2,3}$ With carve-out designs, however, PBMs will work directly with employers and generally handle all aspects of pharmacy benefit administration.

Proponents of carve-in plans report potential advantages of carving in pharmacy benefits, which include the opportunity to streamline and coordinate medical and pharmacy services, integrate medical and pharmacy claims data more easily and subsequently identify value opportunities, and reduce administrative burden by engaging with fewer vendors. ${ }^{2-17}$ Critics, however, suggest that carve-in plans have less auditing transparency, are more rigid in plan design, have inadequate focus on drugs, and receive less significant drug price discounts than their carve-out counterparts..$^{2,3}$

Despite arguments for and against carving in pharmacy benefits, little is known about the effect of carving in pharmacy benefits on medical utilization and cost outcomes among commercial self-insured beneficiaries. Industry-supported literature suggests that carve-in plans are associated with lower hospitalization rates and medical costs and higher engagement in health management programs, but the magnitude of these associations varies. ${ }^{5-17}$ One recently published peer-reviewed article by Smith et al. (2020) suggests that carving in pharmacy benefits among commercial self-insured beneficiaries resulted in lower medical costs, odds of hospitalization, and odds of emergency department (ED) visits, but there is limited peerreviewed literature to corroborate these findings. ${ }^{4}$

Using data from UPMC Health Plan's commercial selfinsured beneficiaries, we sought to expand on Smith et al.'s study to compare the effect of carving in versus carving out pharmacy benefits on specific types of medical utilization, medical costs, and participation in health management programs.

\section{Methods}

\section{Setting, Data Sources, Population, and Study Design}

We used 2018 UPMC Health Plan medical claims to perform a propensity score-matched regression analysis that compared utilization, cost, and health management program participation among members of carve-in versus carve-out plans. UPMC Health Plan is a large health plan in Western Pennsylvania that serves 3.5 million enrollees across all insurance products, including commercial (preferred provider organization [PPO] and health maintenance organization [HMO] products); exchange; Medicare; Medicaid; special needs plans; Children's Health Insurance Program; and workers' compensation products. As part of the commercial insurance product for administrative services only (ASO) employer groups (which includes more than 245,000 members), UPMC Health Plan offers carve-in and carve-out products. For its carve-in clients,
UPMC Health Plan contracts with a large PBM to facilitate network pharmacy rate negotiation, benefit configuration, and claims processing, while retaining formulary development and administration, clinical pharmacy policy, coverage determination adjudication, and customer and provider service in-house.

Study inclusion was limited to members who were continuously enrolled in ASO commercial health plan products from January 1, 2018, to December 31, 2018. We excluded members who had changes in pharmacy coverage (e.g., those who switched from carve-in to carve-out and vice versa) and those who were enrolled in more than 1 insurance product in the study period.

\section{Outcomes}

Our primary outcomes were total medical utilization (defined as the annual number of claims per 1,000 members) and cost outcomes (defined as allowed medical costs per member per month [PMPM]). In addition to assessing total medical utilization and costs, we further categorized these outcomes into the following domains: inpatient admissions; ED visits; outpatient/ambulatory surgery; urgent care; primary care services; specialist services; therapy services (speech, physical, and occupational therapy); diagnostics (laboratory testing and imaging); durable medical equipment (DME); and injectable medical therapy (injectable medications that are billed in medical claims).

We additionally assessed member participation in health plan-based health management programs and further categorized these services into case management, disease management, lifestyle management, and maternity care services. The programs include a range of care modalities, including telephonic support, online modules, group sessions, and self-guided workbooks. ${ }^{18}$ Of note, $84 \%$ of carve-in and $14 \%$ of carve-out members were incentivized to participate in health management programs by their employers. We therefore performed a sensitivity analysis of program participation on just those who were incentivized (Table 1).

\section{Covariates and Statistical Analysis}

We propensity score-matched each carve-in member to 1 carve-out member. We implemented the SAS gmatch algorithm found on HSR CodeXchange, using nearest neighbor matching without replacement. ${ }^{19,20}$ The algorithm chooses the best match for a given data point that minimizes the distance function chosen (weighted sum of absolute differences) to that data point. This is considered a "greedy" algorithm because it minimizes the individual distance and removes those data points from potential subsequent matches. ${ }^{19,20}$

We matched members based on covariates as of December 2018, including age, gender, and age-adjusted Charlson Comorbidity Index (CCI) score to adjust for member comorbidities, ${ }^{21}$ Area Deprivation Index (ADI; defined as a geographic 
TABLE 1 Comparison of Health Management Participation Between Matched Carve-in (N=9,366) and Carve-out $(N=9,366)$ Members $^{\mathrm{a}}$ and Incentivized Carve-in $(N=751)$ and Carve-out $(N=751)$ Members

\begin{tabular}{|c|c|c|c|c|}
\hline & \% Difference & $P$ Value & $\begin{array}{c}\text { \% Difference, } \\
\text { Incentivized } \\
\text { Members }\end{array}$ & $\begin{array}{c}P \text { Value, } \\
\text { Incentivized } \\
\text { Members }\end{array}$ \\
\hline Total health management participation & 4.9 & $<0.001$ & 3.9 & 0.006 \\
\hline Case management & 0.5 & 0.005 & 1.7 & 0.012 \\
\hline Disease management & 0.7 & $<0.001$ & 3.2 & $<0.001$ \\
\hline Lifestyle management & 4.5 & $<0.001$ & 3.2 & 0.007 \\
\hline Maternity case management & 0.0 & 0.946 & 0.8 & 0.076 \\
\hline
\end{tabular}

a Results are based on 1:1 propensity score-matched models, in which continuously enrolled carve-in and carve-out members were matched on age, gender, Charlson

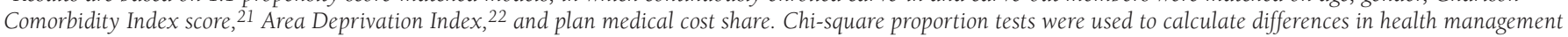
program participation

area-based measure of the socioeconomic deprivation experienced by a neighborhood ${ }^{22}$ ) to account for differences in member demographics and plan medical cost share (defined as percentage of claim expenses paid by the employer over expenses paid by the employer and member) to attempt to account for differences in member plan cost share. Notably, Smith et al.'s study used the same covariate to adjust for plan medical cost share. ${ }^{4}$

We used a gamma model with log link to assess for statistical differences in total medical costs (due to non-normality and skewness of cost data); zero-inflated gamma models with log link to assess for differences in subcategory costs (due to higher percentages of members with $\$ 0$ costs in subcategories); and chi-square proportion testing to assess for differences in utilization and engagement in health management programs. We performed sensitivity analyses that excluded shock claims (i.e., claims that exceeded $\$ 75,000$; Appendix A, available in online article). We used SAS version 9.4 for statistical analysis (SAS Institute, Cary, NC). Statistically significant differences were defined as $P<0.05$.

\section{Results}

We analyzed 9,366 carve-in members belonging to 55 employers and 9,366 carve-out members belonging to 80 employers. Among the propensity score-matched carve-in and carve-out cohorts, average ages were 34.9 and 34.8 years; $53.7 \%$ were female in both groups; average CCI score was 0.68 in both groups; average ADI was 105.1 in both groups; and medical cost share was $85.6 \%$ in both groups (Appendix B, available in online article). $\mathrm{HMO}$ enrollment was $2.9 \%$ in carve-in and $0.9 \%$ in carve-out groups.

Table 2 reflects the results of our claims and cost analyses. Compared with carve-out members, carve-in members had significantly fewer inpatient hospitalizations (9.29 claims/1,000 reduction) and urgent care visits (51.3 claims/1,000 reduction), with no significant difference in total medical utilization. Regarding costs, carve-in members had $\$ 8.73$ lower PMPM costs $(3.7 \%$ reduction, $P=0.005)$ than carve-out members.
The differences in costs were driven by inpatient ( $\$ 10.08$ difference), urgent care (\$0.12 difference), and injectable medical therapy costs ( $\$ 4.32$ difference). Conversely, costs for DME were \$2.14 PMPM more costly in carve-in compared with carve-out plans. These trends were robust in sensitivity analyses that excluded shock claims, except that certain cost differences were no longer significant (total and injectable medical therapy; Appendix A).

Finally, carve-in members experienced $4.9 \%$ higher participation in insurer-based health management programs, primarily because of significantly higher participation in lifestyle management services (Table 1). This trend was maintained in sensitivity analyses with only members who were incentivized to participate in health management programs (Table 1).

\section{Discussion}

In our analysis comparing medical utilization and costs among carve-in versus carve-out members, we found that carving in pharmacy benefits was associated with significantly lower total medical costs and no difference in total medical utilization, with significantly fewer inpatient and urgent care claims and lower costs, significantly lower costs for injectable medical therapy, and significantly higher DME costs. To our knowledge, our analysis is one of the first peer-reviewed publications that demonstrates utilization and cost differences between carving in and carving out pharmacy services.

Our observation that carving in pharmacy benefits was associated with significantly lower medical costs and hospitalizations than carve-out designs is consistent with Smith et al.'s recent study, as well as with industry-supported studies performed by Highmark/Blue Cross Blue Shield, Health Partners, Aetna, and Cigna. ${ }^{4-17}$ Interestingly, our reduction in hospitalizations and total medical costs are similar to what was observed by Smith et al. (we observed a $17.7 \%$ reduction in hospitalizations, whereas they observed a $15 \%$ reduction; we observed a 3.7\% reduction in total medical costs, whereas they observed a 4\% reduction). Despite similar differences in costs, our costs were lower than Smith et al. (\$225.87 vs. \$281 PMPM 
TABLE 2 Comparison of Medical Utilization and Costs for Carve-in (N=9,366) and Carve-out $(N=9,366)$ Members $^{\text {a }}$

\begin{tabular}{|c|c|c|c|c|c|c|c|c|c|c|}
\hline & \multicolumn{5}{|c|}{ Total Medical Utilization (Claims/1,000 Members) } & \multicolumn{5}{|c|}{ Total Medical Costs (PMPM) } \\
\hline & Carve-in & Carve-out & Diff. & \% Diff. & $P$ Value & Carve-in & Carve-out & Diff. & \% Diff. & $P$ Value \\
\hline & 11,401 & 11,598 & $(-197)$ & $(-1.7)$ & 0.456 & $\$ 225.87$ & $\$ 234.60$ & $(-\$ 8.73)$ & $(-3.7)$ & 0.005 \\
\hline Subcategory & \multicolumn{4}{|c|}{ Carve-in vs. Carve-out Difference } & $P$ Value & \multicolumn{4}{|c|}{ Carve-in vs. Carve-out Difference } & $P$ Value \\
\hline Inpatient & \multicolumn{4}{|c|}{$(-9.29)$} & 0.033 & \multicolumn{4}{|c|}{$(-\$ 10.08)$} & $<0.001$ \\
\hline ED & \multicolumn{4}{|c|}{$(-2.88)$} & 0.233 & \multicolumn{4}{|c|}{$\$ 1.50$} & 0.885 \\
\hline Outpatient/ambulatory surgery & \multicolumn{4}{|c|}{$(-10.3)$} & 0.646 & \multicolumn{4}{|c|}{$\$ 1.58$} & 0.149 \\
\hline Urgent care & \multicolumn{4}{|c|}{$(-51.3)$} & $<0.001$ & \multicolumn{4}{|c|}{$(-\$ 0.12)$} & 0.006 \\
\hline Primary care & \multicolumn{4}{|c|}{$(-119)$} & 0.291 & \multicolumn{4}{|c|}{$\$ 0.55$} & 0.989 \\
\hline Specialist & \multicolumn{4}{|c|}{$(-146)$} & 0.670 & \multicolumn{4}{|c|}{$(-\$ 2.31)$} & 0.791 \\
\hline Therapy (PT, OT, speech) & \multicolumn{4}{|c|}{2.14} & 0.295 & \multicolumn{4}{|c|}{$\$ 0.39$} & 0.812 \\
\hline Diagnostics (labs and imaging) & \multicolumn{4}{|c|}{$(-20.1)$} & 0.754 & \multicolumn{4}{|c|}{$\$ 0.24$} & 0.065 \\
\hline DME & \multicolumn{4}{|c|}{26.8} & 0.910 & \multicolumn{4}{|c|}{$\$ 2.14$} & $<0.001$ \\
\hline Injectable medical therapy & \multicolumn{4}{|c|}{6.19} & 0.619 & \multicolumn{4}{|c|}{$(-\$ 4.32)$} & 0.024 \\
\hline
\end{tabular}

a Results are based on 1:1 propensity score-matched models, in which continuously enrolled carve-in and carve-out members were matched on age, gender, Charlson

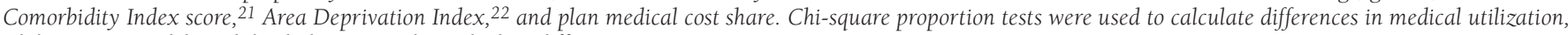
while gamma models with log link were used to calculate differences in costs.

Diff = difference; DME = durable medical equipment; ED=emergency department; OT=occupational therapy; PMPM=per member per month; PT = physical therapy.

for carve-in; $\$ 234.60$ vs. $\$ 292$ for carve-out, respectively). In addition, they observed a significant reduction in ED visits, whereas we observed no significant difference in ED visits.

We urge caution in comparing differences between the studies, however, as there are likely differences in patient populations, plans, and additional factors which render direct comparisons inappropriate. For example, it is possible that we defined total medical costs differently; we defined them as a combination of costs from our utilization subcategories, whereas it is unclear how total medical costs are defined in the Smith et al. study. Second, Smith et al. covered members of different Blue plans across 3 states. It is therefore likely the plans were heterogeneous in how they embraced their approaches to carving in and carving out pharmacy benefits. For instance, some carve-in plans may integrate medical and pharmacy data and act on identified opportunities better than others. Our study, however, was limited to UPMC Health Plan members, so the approach to differences in benefit design was likely more uniform.

Our findings build on the literature by identifying categories that could be responsible for medical cost reduction, including inpatient, urgent care, and injectable medical therapy. These trends could be explained by several factors. First, health plans can leverage the combined medical and pharmacy data of carve-in members to gain a more comprehensive view of their member needs, allowing for more effective identification of those members who might benefit most from health management programs. Although PBMs do provide medication management programs in carve-out plans based on pharmacy claims, medical claims provide more robust information by which targeted interventions for high-risk patients can be designed. For example, at UPMC Health Plan, the benefit of carve-in plans is facilitated by Health Planet, an information technology platform that provides a comprehensive view of members using integrated medical and pharmacy data and houses all case interactions by staff (social, financial, and clinical). ${ }^{23}$ In contrast, carve-out designs generally do not have efficient ways to coordinate complex medical records with pharmacy claims and require data exchanges between vendors and insurers.

Second, health plans could use comprehensive data from carve-in members to identify those who might benefit from care management programs. This is supported by findings from our study and a previous study done by Cigna (2020), both of which indicate that carve-in members have higher engagement and/or participation in health plan-based management programs. ${ }^{13}$

Furthermore, carving in pharmacy benefits allows for health plans to more easily identify members who have medication optimization opportunities based on their medical conditions. For instance, access to comprehensive data could assist health plans in identifying and reaching out to patients who have congestive heart failure and high-risk clinical features who would benefit from additional pharmacotherapy. Also, given our observed cost reduction for injectable medical therapies, a comprehensive review of drug use from pharmacy and medical claims could allow for identification of value opportunities for specialty drugs.

Since carve-in plans manage medical and pharmacy benefits, they have more authority to optimize pharmacy benefits with the goal of reducing medical utilization. For example, recent studies demonstrate that integrated Medicare Advantage/ 
Part D plans have decreased patient cost sharing and increased spending for chronic disease medications compared with stand-alone Part D plans. ${ }^{24,25}$ While these differences could be related to differences in plan design and covered populations, these studies suggest that integrated plans may be more motivated to increase drug adherence and appropriate drug use to offset downstream medical costs, whereas stand-alone Part D plans may not have the same prerogative.

Importantly, we observed that the domains with the largest reductions in costs between carve-in and carve-out members included inpatient visits and injectable medical therapy. Although more research is needed to explore the drivers of these differences, if carve-in members truly experienced improved outcomes from more appropriate medication use, better medication adherence, and higher engagement with health management programs, then they could in fact appreciate reduced utilization of these services. Conversely, it is unclear why DME costs increased for carve-in members while utilization did not increase. While we accounted for differences in the presence of comorbidities using CCI scores, it is possible that differences in severity of comorbidities between groups could be an important factor.

\section{Limitations}

Our study has limitations to consider. First, the study was confined to ASO commercial health plan members from a single health care organization, so findings may not be generalizable to other health plans and systems.

Second, while we tried to account for plan design differences by accounting for employer versus member cost share, we may not have accounted for all individual plan differences. It is therefore possible that specific differences in benefit design that we could not account for could have steered members to differing sites of care.

Third, we did not have adequate access to pharmacy utilization and cost data for our carve-out clients, so we were unable to compare the effect of carving in pharmacy benefits on pharmacy claims and costs. It is therefore unclear whether medical savings translate to total cost savings or whether savings from medical costs may have been substituted by or offset by increased drug costs, thus, leading to similar or increased total costs. The literature on the relationship between medical and pharmacy costs suggests that increased drug costs may offset nondrug savings but to varying degrees. ${ }^{26-29}$ For instance, a study by Roebuck et al. (2015) found that a $1 \%$ increase in drug spending was associated with a 0.04\%-0.167\% decrease in nondrug spending in Medicaid, ${ }^{26}$ while in Medicare, estimates vary-the Congressional Budget Office suggests that a $1 \%$ increase in drug spending may lead to $0.2 \%$ decrease in utilization, ${ }^{27}$ and Shang and Goldman (2007) suggest that a $\$ 1$ increase in prescription drug spending is associated with a $\$ 2.06$ reduction in medical costs. ${ }^{29}$ Although these studies are focused on different populations (Medicare and Medicaid) than ours, they suggest that increased medication use may substitute or prevent the need for health care utilization, although it is unclear whether medical savings are completely offset by increased drug costs, especially among commercial enrollees.

\section{Conclusions}

As employers attempt to understand the value of carving in versus carving out pharmacy benefits to health plans, our findings suggest that carve-in members have reduced medical costs and utilization compared with their counterparts. Taken together, our findings can be instrumental in informing employer decision-making processes and, in turn, reducing costs of care for the health care system.

\section{Authors}

NATASHA PAREKH, MD, MS, and YAN HUANG, MS, UPMC Centers for Value-Based Pharmacy Initiatives and High-Value Health Care, UPMC Insurance Services Division, Pittsburgh, Pennsylvania. SARAH PAPA, MS; ALEK DRNACH, MS; and LAURA SPIEGEL, BS, WorkPartners, UPMC Insurance Services Division, Pittsburgh, Pennsylvania. CHRONIS MANOLIS, RPh, Pharmacy Services, UPMC Insurance Services Division, Pittsburgh, Pennsylvania. CHESTER B. GOOD, MD, MPH, UPMC Centers for Value-Based Pharmacy Initiatives and High-Value Health Care, UPMC Insurance Services Division and University of Pittsburgh Division of General Internal Medicine, Pittsburgh, Pennsylvania.

AUTHOR CORRESPONDENCE: Natasha Parekh, MD, MS, Queen's Health Systems, 1301 Punchbowl St., Honolulu, HI 96813. Tel.: 808.691.7739; Email: nparekh@queens.org.

\section{DISCLOSURES}

No outside funding supported this study. Parekh was and Huang and Good are employed by the UPMC Centers for High-Value Health Care and ValueBased Pharmacy Initiatives. Manolis is employed by the UPMC Health Plan within the UPMC Insurance Services Division. Papa, Drnach, and Spiegel are employed by WorkPartners within the UPMC Insurance Services Division.

\section{ACKNOWLEDGMENTS}

The authors acknowledge Jennie Wheeler, MBA, for her guidance on data analysis and interpretation and Elizabeth C.S. Swart, BA, and Lynn Neilson, $\mathrm{PhD}$, for their help in understanding the literature on this topic.

\section{REFERENCES}

1. PwC Health Research Institute. Medical cost trend: behind the numbers 2020. June 2019. Available at: https://www.pwc.com/us/en/industries/ health-industries/assets/pwc-hri-behind-the-numbers-2020.pdf. Accessed September 2, 2020.

2. Anderson BN, Reed A. PBM best practice series. Carve-in vs carve-out programs. December 2019. Available at: https://milliman-cdn.azureedge. net/-/media/milliman/pdfs/articles/best-practices-pharmacy-benefits-carvein-carve-out.ashx. Accessed September 14, 2020. 
3. Weaver K. Pharmacy management: carving in versus carving out. What's right for your business? Lockton Companies. December 2017. Available at: https://www.lockton.com/whitepapers/Weaver_Pharmacy_Management_ November.pdf. Accessed September 2, 2020.

4. Smith JJ, Qiu L, Lam SV, Lockwood CM, Pegus C, Gleason PP. Medical costs and health care utilization among self-insured members with carve-in versus carve-out pharmacy benefits. J Manag Care Spec Pharm. 2020;26(6):766-74. Available at: https://www.jmcp.org/doi/full/10.18553/ jmcp.2020.19411.

5. Highmark Blue Cross Blue Shield. A prescription for savings - integrate medical and pharmacy benefits. Provider News. Issue 5. 2017. Available at: https://hbs.highmarkprc.com/pnews/pn-5-2017/prescription_for_savings. html. Accessed September 2, 2020.

6. Blue Cross Blue Shield Rhode Island. The importance of integration. May 2018. Available at: https://www.bcbsri.com/sites/default/files/organfiles/ Rx-Integration-Story-7272018.pdf?mkt_tok=eyJpIjoiTkRZd09UbGlOREpq TmpneCIsInQiOiJBOTR2YWdIYVBqSTISTnU4eGFlc2wrVDJlUHVXblwvU3 h4TUltblJPVUVWZG9aYmRjWElwK1lheGJGR2orVGZsamYycHpwZlFDSH IxU3NcL3JEbkhFREloTmJHUWZmUVlaZEFXaXlTSmpsMjd2QXNaRlwv R2tReDRuWU83dFRMY1NaNCJ9. Accessed September 2, 2020.

7. Wells P, Ness D. Pharmacy carve-in: the benefit of integrated benefits. Washington Healthcare News. Available at: https://www.healthcarenewssite. com/newsletters/wa-premera-0412.pdf. Accessed September 2, 2020.

8. Culley E, Williams LC, Thomas L. Pharmacy benefit carve-in: the right prescription for cost savings. Benefits Compensation Digest. 2010;47(11):22-26.

9. Smith-McLallen A. Effects of pharmacy benefit carve-in on utilization and medical costs: a three-year study. Benefits Magazine. 2012;49(2):1-6. Available at: https://www.ifebp.org/inforequest/0161568.pdf. Accessed September 2, 2020.

10. Gleason P, Qui Y, Bowen K, Johnson SV, Yoder D. Economic and event outcomes of members with carve-in versus carve-out pharmacy benefits: a 2-year cohort study. Poster presented at: AMCP 2014 Nexus; October 8, 2014; Boston, MA. Available at: https://www.primetherapeutics.com/content/ dam/corporate/Documents/Newsroom/PrimeInsights/2014/researchposters/1014fall-carve-in-vs-carve-out.pdf. Accessed September 2, 2020.

11. HealthPartners. Health Partners pharmacy integration study. June 2010. Available at: https://www.cigna.com/assets/docs/newsroom/450283pharmstudy-br3-final.pdf. Accessed September 2, 2020.

12. Cigna. A proven formula for better outcomes: the value of pharmacy integration. October 2016. Available at: https://www.cigna.com/assets/ docs/business/pharmacy-value-of-integration-white-paper.pdf. Accessed September 2, 2020.

13. Cigna. Combining medical, pharmacy, and behavioral benefits delivers annual savings of more than $\$ 850$ per customer with an identified health improvement opportunity. News release. January 6 , 2020. Available at: https://www.cigna.com/newsroom/news-releases/2020/ combining-medical-pharmacy-and-behavioral-benefits-delivers-annualsavings-of-more-than-850-per-customer-with-an-identified-opportunity. Accessed September 2, 2020.

14. Cigna. Better together: CIGNA pharmacy management + CIGNA medical. 2010. Available at: https://www.cigna.com/assets/docs/newsroom/ better-together.pdf. Accessed September 2, 2020.
15. Aetna. Integration is the answer. November 2018. Available at: http:// www.aetna.com/pdf/Integrated_pharmacy.pdf. Accessed September 2, 2020.

16. Optum. OptumRx study shows an average savings of \$16 PMPM medical savings. May 2019. Available at: https://www.optum.com/content/ dam/optum3/optum/en/resources/PDFs/M54610-W4-Optum-2019-MacroStudy_3.1.pdf. Accessed September 2, 2020.

17. Brown S, Whaley S. Pharmacy benefits: are carve-outs on the way out? Accenture. 2019. Available at: https://www.accenture.com/us-en/insights/ health/pharmacy-benefits-carve-outs-way-out\#: :text=Accenture $\% 20$ research $\% 20$ reveals $\% 20$ that $\% 20$ more, could $\% 20$ actually $\% 2$ reverse $\% 20$ this\%20trend. Accessed September 2, 2020.

18. UPMC Health Plan. Medical management. December 1, 2017. Available at: https://www.upmchealthplan.com/docs/providers/2017_ ProviderManual_G.pdf. Accessed September 2, 2020.

19. Dutta M, Natarajan A. Redesigning control using the GMATCH algorithm to isolate impact of a specific marketing intervention from overlapping solicitations. SAS paper 11660-2016. 2016. Available at: https:// support.sas.com/resources/papers/proceedings16/11660-2016.pdf. Accessed September 2, 2020.

20. Parsons S. Lori. Reducing bias in a propensity score matched-pair sample using greedy matching techniques. SAS paper 214-26. Proceedings of the SUGI 26, SAS Institute. Available at http://www2.sas.com/ proceedings/sugi26/p214-26.pdf. Accessed September 2, 2020.

21. Charlson M, Szatrowski TP, Peterson J, Gold J. Validation of a combined comorbidity index. J Clin Epidemiol. 1994;47(11):1245-51.

22. Health Services Advisory Group. Area Deprivation Index. Available at: https://www.hsag.com/es/medicare-providers/patient-and-family-centeredcare/disparities/area-deprivation-index/. Accessed September 2, 2020.

23. UPMC. UPMC is life-changing medicine: 2017 year in review. 2018. Available at: https://www.upmc.com/-/media/upmc/about/facts/documents/ year-in-review-2017.pdf. Accessed September 2, 2020.

24. Starc A, Town R. Internalizing behavioral externalities: benefit integration in health insurance. NBER Working Paper 21783. January 2016. Available at: https://economics.yale.edu/sites/default/files/internalizing_ behavioral_externalities_-_town.pdf. Accessed September 2, 2020.

25. Lavetti K, Simon K. Strategic formulary design in Medicare Part B plans. Am Econ J Econ Policy. 2018;10(3):154-92.

26. Roebuck MC, Dougherty JS, Kaestner R, Miller LM. Increased use of prescription drugs reduces medical costs in Medicaid populations. Health Aff (Millwood). 2015;34(9):1586-93.

27. Hayford T, Buntin M. Offsetting effects of prescription drug use on Medicare's spending for medical services. Congressional Budget Office. November 2012. Available at: http://www.cbo.gov/sites/default/files/43741MedicalOffsets-11-29-12.pdf. Accessed September 2, 2020.

28. Zuvekas SH. Prescription drugs and the changing patterns of treatment for mental disorders, 1996-2001. Health Aff (Millwood). 2005;24(1):195-205.

29. Shang B, Goldman DP. Prescription drug coverage and elderly Medicare spending. National Bureau of Economic Research. Working paper 13358. September 2007. Available at: https://www.nber.org/papers/wl3358.pdf. Accessed September 2, 2020. 
APPENDIX A Sensitivity Analysis: Comparison of Medical Utilization and Costs for Carve-in $(\mathrm{N}=9,366)$ and Carve-out $(N=9,366 \text { ) Members, Excluding Shock Claims (Claims that Exceed } \$ 75,000)^{a}$

\begin{tabular}{|c|c|c|c|c|c|c|c|c|c|c|}
\hline & \multicolumn{5}{|c|}{ Total Medical Utilization (Claims/1,000 Members) } & \multicolumn{5}{|c|}{ Total Medical Costs (PMPM) } \\
\hline & Carve-in & Carve-out & Diff. & \% Diff. & $P$ Value & Carve-in & Carve-out & Diff. & \% Diff. & $P$ Value \\
\hline & 11,400 & 11,597 & $(-196)$ & $(-1.7)$ & 0.456 & $\$ 220.46$ & $\$ 223.68$ & $(-\$ 3.21)$ & $(-1.4)$ & 0.594 \\
\hline Subcategory & \multicolumn{4}{|c|}{ Carve-in vs. Carve-out Difference } & $P$ Value & \multicolumn{4}{|c|}{ Carve-in vs. Carve-out Difference } & $P$ Value \\
\hline Inpatient & \multicolumn{4}{|c|}{$(-8.97)$} & 0.029 & \multicolumn{4}{|c|}{$(-\$ 7.46)$} & $<0.001$ \\
\hline ED & \multicolumn{4}{|c|}{$(-2.88)$} & 0.233 & \multicolumn{4}{|c|}{$\$ 1.50$} & 0.885 \\
\hline Outpatient/ambulatory surgery & \multicolumn{4}{|c|}{$(-10.4)$} & 0.630 & \multicolumn{4}{|c|}{$\$ 0.52$} & 0.565 \\
\hline Urgent care & \multicolumn{4}{|c|}{$(-51.3)$} & $<0.001$ & \multicolumn{4}{|c|}{$(-\$ 0.12)$} & 0.006 \\
\hline Primary care & \multicolumn{4}{|c|}{$(-119)$} & 0.291 & \multicolumn{4}{|c|}{$\$ 0.55$} & 0.989 \\
\hline Specialist & \multicolumn{4}{|c|}{$(-146)$} & 0.670 & \multicolumn{4}{|c|}{$(-\$ 2.31)$} & 0.791 \\
\hline Therapy (PT, OT, speech) & \multicolumn{4}{|c|}{2.14} & 0.295 & \multicolumn{4}{|c|}{$\$ 0.39$} & 0.812 \\
\hline Diagnostics (labs and imaging) & \multicolumn{4}{|c|}{$(-20.2)$} & 0.754 & \multicolumn{4}{|c|}{$\$ 0.16$} & 0.079 \\
\hline $\mathrm{DME}$ & \multicolumn{4}{|c|}{26.7} & 0.892 & \multicolumn{4}{|c|}{$\$ 1.67$} & 0.003 \\
\hline Injectable medical therapy & \multicolumn{4}{|c|}{6.73} & 0.619 & \multicolumn{4}{|c|}{$\$ 0.23$} & 0.983 \\
\hline
\end{tabular}




\begin{tabular}{|c|c|c|c|}
\hline APPENDIX B & $\begin{array}{l}\text { Baseline De } \\
\text { Propensity S } \\
\text { and Carve-C }\end{array}$ & $\begin{array}{l}\text { graphics } \\
\text { re-Matche } \\
\text { Members }\end{array}$ & Carve-in \\
\hline & $\begin{array}{l}\text { Carve-in } \\
\text { Members }\end{array}$ & $\begin{array}{l}\text { Carve-out } \\
\text { Members }\end{array}$ & $P$ Value \\
\hline $\mathrm{N}$ & 9,366 & 9,366 & \\
\hline Mean age (SD) & $34.9(18.8)$ & $34.8(18.8)$ & 0.967 \\
\hline Female, \% & 53.7 & 53.7 & 1.000 \\
\hline Average CCI score & 0.68 & 0.68 & 1.000 \\
\hline Mean ADI (SD) & $105.1(8.6)$ & $105.1(8.6)$ & 0.970 \\
\hline Medical cost share, ${ }^{\text {a }} \%$ & 85.6 & 85.6 & 0.820 \\
\hline $\begin{array}{l}\text { aPercentage of medical cost } \\
\text { is paid out by the employer } \\
\text { member. } \\
\text { ADI=Area Deprivation Ind } \\
\text { SD=standard deviation. }\end{array}$ & $\begin{array}{l}\text { share is defined as } \\
\text { over the expenses } t \\
\text { ex; CCI = age-adjus }\end{array}$ & $\begin{array}{l}\text { entage of clai } \\
\text { are paid by th } \\
\text { Charlson Con }\end{array}$ & $\begin{array}{l}\text { penses that } \\
\text { ployer and } \\
\text { dity Index; }\end{array}$ \\
\hline
\end{tabular}

